\title{
The Role of Attitude Strength in Predicting Organ Donation Behaviour by Implicit and Explicit Attitude Measures
}

\author{
Gundula Hübner1,2, Anja Mohs', Lars Eric Petersen'1 \\ ${ }^{1}$ Martin-Luther-University Halle-Wittenberg, Halle, Germany \\ ${ }^{2}$ MSH Medical School Hamburg, Hamburg, Germany \\ Email: gundula.huebner@psych.uni-halle.de
}

Received 20 August 2014; revised 20 September 2014; accepted 8 October 2014

Copyright (C 2014 by authors and Scientific Research Publishing Inc.

This work is licensed under the Creative Commons Attribution International License (CC BY). http://creativecommons.org/licenses/by/4.0/

(c) (i) Open Access

\begin{abstract}
Explicit attitude measures seem to be rather poor predictors of organ donation behaviour. This study examined whether implicit attitude measures acted as better predictors. Special attention was paid to the moderating role played by attitude strength in predicting deliberate donation behaviour. In this study $(N=78)$, explicit and implicit measures of attitudes towards organ donation, as well as behavioural commitment, were assessed. Implicit associations were measured by an Implicit Association Test; five constructs assessed self-reported-understood as reflected-attitude strength. The explicit attitude measure appeared to be the best single predictor of whether the participant ended up taking an organ donor card. More importantly, test results demonstrated the moderating role of attitude strength. In the case of low attitude strength, the likelihood of taking a donor card increased with an increasing positive implicit association. In contrast, increasing strength was associated with a weaker link between card taking and the implicit attitude measure. The results are discussed in light of the power of implicit associations to predict more deliberate behaviours.
\end{abstract}

Keywords

Health Attitudes and Behaviour, Implicit and Explicit Attitude Measures, Organ Donation

\section{Introduction}

Over the past 20 years, a gap has been observed between positive attitudes toward organ donation and their lack of translation into behavioural commitment in terms of organ donor card signing, e.g. [1]. This attitude-behaviour 
gap may be in part due to two conceptual problems. Firstly, until recently, research on organ donation focus on cognitive attitudes, neglecting feelings associated with organ donation [2]. Secondly, researchers investigating attitudes toward organ donation commonly rely on explicit, self-reported attitude measures, e.g. [2]. Two main limitations challenge the validity of self-reporting, cf. [3]. Generally, factors such as demand characteristics or self-presentation concerns may influence self-reporting. Furthermore, they afford introspection to indicate reliable attitude scores. Indirect attitude measures may circumvent these limitations.

There are good reasons to expect that implicit attitude measures add to the understanding of organ donation behaviour. Organ donation is socially desired and has moral implications, since to decide against donation is equal to a decision against saving lives. Likely, these pro-donation expectations support overly positive direct assessments and thus mask critical evaluations. Additionally, considering becoming an organ donor prompts reflection on one's own mortality and thus is likely to inhibit introspection [4]. So far, the impact of implicit associations on organ donation remains an open question.

\subsection{Implicit Attitude Measures}

The most widely used approach to measure implicit social cognitions is the Implicit Association Test (IAT) [5]. Basically, the IAT is a computerised sorting task. It measures the strength of associations between constructs by forcing respondents to associate themselves with the same response key. Sorting is assumed to be easier and therefore faster, if two highly associated concepts share the same response keys, compared with sharing different ones [6] [7]. The IAT is a popular method to investigate social phenomena, such as health protection (e.g. [8]) or self-concept of anxiety (e.g. [9]). Referring to organ donation, the IAT-anxiety is of special interest, since organ donation is connected to negative feelings and cognitions, particularly about death and dying. In the present article, the IAT-anxiety is adopted to provide an implicit measure of organ donation attitudes.

\subsection{The IAT as a Predictor of Behaviours}

Several studies provide evidence that the IAT can predict behaviours in some but not all cases, cf. [10]. Implicit measures seem to predict particularly spontaneous behaviours such as white Americans' non-verbal behaviours toward African-Americans, cf. [11]. The IAT can even predict behaviours under more volitional control, such as voting [12] or condom use [8]. However, it fails to predict the choice of a candy bar versus an apple [13]. Moderator effects offer one possible explanation for these inconsistent results. For example, Perugini [14] found implicit and explicit attitude measures to interactively predict smoking. Additionally, individual differences in automatic evaluations at the associative level seem to moderate the IAT's predictive validity [15]. Overviews of variables moderating the implicit-explicit consistency provide a better understanding of these attitude indicators' interrelation [10] [16]. The present paper focuses on one possible moderator on the implicit-explicit relation in predicting behaviours, namely, attitude strength.

\subsection{Attitude Strength as a Moderator}

Strong attitudes can be defined as attitudes that are stable, resistant to changes, and that influence thoughts and behaviours [17]. However, attitude strength seems to be a heterogeneous construct. Several self-reported measures of attitude strength exist, including attitude importance, certainty, knowledge or cognitive elaboration (see [17] [18] for an overview). These direct measures have in common that they are based on reflected assessments. Consequently, we understand self-reported attitude strength based on reflection.

Strong attitudes are associated with a higher attitude-behaviour consistency, e.g. [18] [19]. Moreover, attitude strength moderates the consistency of implicit-explicit attitude measures and their relation in predicting behaviours (see [16] for an overview; [20]). For example, stronger attitudes - assessed by a combined self-reported and therefore reflected strength measure including importance and thought frequency-were associated with greater consistency between IAT and self-reported attitude measures than weaker attitudes [21]. Additionally, Conner and colleagues (Study 2) [20] showed that the power of an IAT-measure in predicting consumption of sweets became stronger as levels of self-reported consumption habits increased, indicating more practised and automatic behaviours. Conversely, increased level of need for cognition-indicating increased motivation and opportunity to reflect one's attitude - was associated with a stronger impact of the explicit measure on behaviours, while the implicit measure remained unaffected. 
So far, the reported findings are in line with the motivation and opportunity as determinants of the behaviour model's assumption (MODE) [22] that strongly associated evaluations are automatically activated and guide behaviours. Conversely, increased deliberation increases the impact of explicit attitude measures. Likewise, these findings - as Conner and colleagues [20] point out — are in accord with the assumption that implicit and explicit attitude measures represent different influential processes that can interact with each other [23] [24]. However, research on representational strength [16] as a moderator of the implicit-explicit relation has relied on everyday content behaviours, such as food choice [20] or social groups and political issues [21]. In contrast, the decision to become a potential organ donor by signing a donor card clearly affords cognitive deliberation.

It remains an open question whether the above-reviewed assumptions and results can be generalised to this specific case of deliberate behaviours. If so, based on the MODE model in the deliberate mode, explicit attitude measures capturing conscious elaboration should predict donation behaviour while the impact of implicit associations should be minimal [22]. Further, research on attitude strength shows evidence for an increasing attitudebehaviour relation as attitude strength increases, e.g. [17]. Similarly, according to the dual-process approach [23] [24], the relation between explicit attitude measures and behaviours should increase as systematic and effortful information processing increases, while the predictive power of implicit attitude measure should remain unaffected. However, a contrasting assumption can be derived from the reflective-impulsive model (RIM) [24].

The RIM presents two information-processing systems that operate in parallel and interact with one another. The reflective system is characterised as an explicit decision-making process, while the impulsive system elicits behaviours through simple associative links and motivational orientations. Both the systems can activate behavioural schemata that, in turn, activate overt behaviours. Simultaneously, more than one schema can receive activation, even from both systems. Which behavioural schema will prevail depends on the conditions and on the strength of the activation for each schema. This offers a new perspective on the role of implicit associations in the case of more deliberative processing. Strong attitudes toward deliberative behaviours result from reflecting on behavioural outcomes and integrating them into an overall judgment, e.g. [25]. Furthermore, implicit associations stem from automatic emotional reactions to stimuli while explicit processes are more cognitively controlled [26]. Thus, in the case of higher attitude strength, we expect the reflective system to dominate the execution of deliberate behaviours. Contrastingly, in the case of weaker strength, prior evaluations are unlikely and impulsive reactions may be inferred as additional and affective information [27]. Correspondingly, we hypothesise that the impact of implicit associations on deliberate behaviours is stronger when the attitude strength is weak. Since organ donation is likely to activate associations with death and dying, we expect a negative IAT effect.

In sum, the present contribution aims to understand the role of implicit associations in the organ donation decision and the moderating impact of attitude strength on the implicit association-behaviour relation.

\section{Method}

\subsection{Sample}

The sample consisted of 90 participants recruited on university campus. Nine participants were discarded for incomplete questionnaires, and three due to computer failure. Of the remaining 78 participants, $48.7 \%$ were women, $51.3 \%$ were men. Ages ranged from 19 to 33 years, with an average age of 22.4. The majority held a university entrance qualification (96.2\%) and were students (91.0\%). Political (24.3\%), nature (16.2\%), and economic $(16.2 \%)$ sciences were the most frequent subjects. Students of medicine and psychology, and organ-donor card holders were excluded from the survey.

\subsection{IAT Procedure and Stimuli}

Procedures and IAT-donation stimuli were modelled closely after Egloff and colleagues [28], following the standard five-step IAT sequence, cf. [5]. The categorisation into organ donation and non-organ donation categories was combined with the classification of anxiety and calmness items. Five stimuli each were presented from organ donor (e.g. transplantation) and non-organ donor (e.g. transport system) categories as well as items from anxiety (e.g. afraid) and calmness (e.g. relaxed) categories. Note that the original German words were single, comparable in length and first letter. Their comprehensibility, distinctness and perceived valence were tested in a pre-study $(N=18)$. Items that differed significantly in valence, were miscategorised, or were unknown to any person were excluded from the final list. The IAT was introduced as a categorisation task related 
to organ donation. Participants were told to be as accurate as possible, while going as quickly as possible; errors were marked. Each participant completed the measures anonymously while in a small group. To control for sequence effects, half of the participants first completed the IAT and next the questionnaire including the explicit measures; the other half received the reversed sequence. Furthermore, we counterbalanced the block order. Nearly half of the respondents $(n=41)$ received the compatible block first (organ donation + anxiety) while the other half $(n=37)$ started with the incompatible block (organ donation + calmness).

IAT data were treated using the improved scoring algorithm $\left(\mathrm{D}_{1}\right.$ measure) [29]. The IAT effect was calculated by taking the latency for the organ donor + calmness task (incompatible task) minus the latency for the organ donor + anxiety task (compatible task). Scores were recorded, so that positive scores indicated greater facility for the organ donor + calmness task and more positive implicit donation attitudes.

\subsection{Explicit Variables}

To measure explicit attitude towards organ donation a four-item semantic differential scale had participants respond to "I think organ donation is..." on four adjective pairs (senseless/useful, dispensable/desirable, bad/good, negative/positive); 8-point bipolar scales ranging from -4 to $+4(\alpha=0.86)$.

In total, five constructs assessed attitude strength:

1) The first strength indicator was cognitive elaboration on signing an organ donor card. Participants were asked to self-report whether they had reflected (thought about/deliberate) on signing a donor card before participating in our survey. Two groups were categorised: participants who had not reflected on signing were coded as "low strength" (0), those who had as "high strength" group (1). To validate this categorisation, four further attitude strength indicator were assessed; 2) Five statements assessed issue involvement ( $\alpha=0.82)$; participants rated how strongly they disagreed $(0=$ not at all) or agreed $(5=$ strongly). An item example is "Organ donation is an important topic to me". The mean of the items served as issue involvement indicator; 3) One item measured attitude certainty. Participants indicated how strongly they agreed with the statement "I am well enough informed to make a decision to sign an organ donor card or not" $(0=$ do not agree at all to $5=$ strongly agree $)$; 4) Next, participants rated their subjective knowledge on a 4-point scale ranging from 0 (not at all informed) to 3 (very well informed); 5) To assess communication activity, participants were asked how frequently they communicated about organ donation $(0=$ never to $2=$ occasionally). Out of the last four indicators, we aimed to construct a compound strength measure.

Behaviour was assessed as taking (1) or not taking (0) an organ donor card after the survey. For this purpose, each questionnaire included a donor card on the second to last page, to be removed easily and anonymously. Participants were not informed about this card before.

\section{Results}

\subsection{Descriptive Results}

Almost equal parts of the sample had either reflected on signing an organ donor card $(47.4 \%, n=37$; high strength group) or not $(52.6 \%, n=41$; low strength group). Average issue involvement was rather strong ( $M=$ $3.75, S D=0.86)$ while attitude certainty was below the midpoint $(M=2.73, S D=1.21)$. Subjective knowledge also was low; most participants $(76.9 \%)$ indicated they felt little informed about organ donation, while only $13.6 \%$ felt well or very well informed. Additionally, none of the respondents communicated occasionally about organ donation with others, $76.9 \%$ only seldom, and $23.1 \%$ had never done so.

The explicitly assessed attitude toward organ donation was high positive on average $(M=3.14, S D=0.75)$ while the implicit association was only slightly positive $(M=0.10, S D=0.42)$. The majority of respondents $(60.3 \%)$ took the donor card after answering the questionnaire. The variables' intercorrelations (Table 1) remained below $r=0.50$.

\subsection{Compound Strength Measure}

To construct a compound attitude strength measure we conducted a factor analysis. Unfortunately, only the statements of the assessed strength indicators involvement and attitude certainty could be involved in that analysis, since subjective knowledge as well as communication activity were extremely unequally distributed, as described. Consequently, we abstained from further analyses with those measures. The rotated factor loadings 
Table 1. Correlations between explicit (explicit attitude) and implicit attitude (implicit association) measure, attitude strength indicators and behaviour $(N=78)$.

\begin{tabular}{cccccccc}
\hline Variable & EA & IA & CE & I & AC & SK & CF \\
\hline Explicit attitude (EA) & 1.00 & & & & & \\
Implicit association (IA) & 0.13 & 1.00 & & & & \\
Cognitive elaboration (CE) & 0.07 & $0.26^{*}$ & 1.00 & & & \\
Involvement (I) & $0.26^{*}$ & 0.20 & $0.38^{* *}$ & 1.00 & & \\
Attitude certainty (AC) & 0.15 & 0.18 & $0.32^{* *}$ & 0.15 & 1.00 & \\
Subjective knowledge (SK) & 0.13 & 0.14 & $0.33^{* *}$ & 0.09 & $0.28^{*}$ & 1.00 & \\
Communication frequency (CF) & 0.15 & 0.09 & $0.28^{*}$ & $0.37^{* *}$ & 0.03 & 0.01 & 1.00 \\
Behaviour (BE) & $0.47^{* * *}$ & 0.17 & $0.19^{* *}$ & 1.00 & 0.15 & 0.15 & 0.18 \\
\hline
\end{tabular}

Note: ${ }^{(*)} p<0.10 ;{ }^{*} p<0.05 ;{ }^{* *} p<0.01 ;{ }^{* * *} p<0.001$.

showed that involvement's items and the attitude certainty statement loaded on two different factors. Therefore, in contrast to Nosek [21]—but in accord with others, e.g. [18]—we could not construct a compound strength measure and evaluated the remaining three concepts, namely cognitive elaboration, involvement, and attitude certainty, independently.

\subsection{Implicit and Explicit Attitude Relation}

A significant overall IAT effect was observed. However, against expectation the IAT measure provided evidence for positive implicit associations $(M=0.10, S D=0.42 ; t(77)=2.06, p<0.05)$, indicating a greater facility for the organ donor + calmness task. The explicit and implicit attitude measures did not correlate significantly $(r=0.13, n s . ;$ Table 1$)$.

\subsection{Predicting Behaviours}

To investigate both the unique contribution of the implicit and explicit attitude measure, as well as the moderator effect of attitude strength, hierarchical logistic regressions were performed, using hierarchically well-formulated models. The continuous attitude variables were centred [30] [31].

Firstly, the impact of implicit and explicit attitude measures on behaviour was tested. At the first step, both variables were entered as predictors of taking a donor card. The model explained $30 \%$ of variation in behaviour (Nagelkerkes $R^{2}$ ) with the explicit attitude measure being the only significant predictor $(B=1.55, S E=0.43, p<$ 0.001 ; implicit association: $B=0.71, S E=0.64, p=0.27$ ). To explore a possible interaction, in a second step, the concept's multiplicative term was entered, improving the overall prediction only moderately by $4 \%$ (Nagelkerkes $R^{2}=0.34, R^{2}$ change $\left.=4 \% ; \chi^{2}=2.96, p=0.085\right)$. This trend towards significance was reflected in the interaction term $(B=2.10, S E=1.27, p=0.097)$.

Secondly, the moderating role of the attitude strength measures was calculated. The analysis was conducted consecutively with the three attitude strength indicators-cognitive elaboration, involvement, and attitude certainty. In each analysis, in the first step the implicit and explicit attitude measures, together with one of the three attitude strength indicators, were entered as predictors of taking a donor card. The second step involved all two-way interactions while the three-way interaction was entered in step three (Table 2).

The first analysis tested the moderating impact of cognitive elaboration. The first step's model explained $33.3 \%$ of variation in behaviour (Nagelkerkes $R^{2}$ ), with the explicit attitude being the only significant predictor $(B=1.61, S E=0.45, p<0.01$; implicit association: $B=0.52, S E=0.67, p=0.44$; cognitive elaboration: $B=$ $0.83, S E=0.56, p=0.14)$. Next, the two-way interaction terms were entered. This improved the model fit $\left(\chi^{2}(6)\right.$ $=34.36, p<0.001)$ over and above the first model, implying a significant omnibus interaction effect $\left(\chi^{2}\right.$ change $(3)=12.35, p<0.01)$. The interaction between the implicit association and attitude strength was the only significant interaction term $(B=-3.89, S E=1.57, p<0.05)$. The multiplicative term between the implicit and explicit attitude measure showed a trend towards significance $(B=2.81, S E=1.68, p=0.095)$. Jointly, the two-way interaction terms increased the explained amount of variation in the behaviour by $14.9 \%$ to $48.2 \%$. Finally, the 
Table 2. Results of the logistic regression analyses to predict taking or not an organ donor card with explicit (explicit attitude) and implicit attitude (implicit association) measure, three attitude strength indicators and their interactions.

\begin{tabular}{|c|c|c|c|c|c|c|c|c|c|}
\hline \multirow[b]{2}{*}{ Variable } & \multicolumn{3}{|c|}{$\begin{array}{l}\text { Attitude strength }=\text { cognitive } \\
\text { elaboration }\end{array}$} & \multicolumn{3}{|c|}{ Attitude strength $=$ involvement } & \multicolumn{3}{|c|}{ Attitude strength $=$ attitude certainty } \\
\hline & $B$ & $S E$ & Wald & $B$ & $S E$ & Wald & $B$ & $S E$ & Wald \\
\hline \multicolumn{10}{|l|}{ Step 1} \\
\hline Explicit attitude (EA) & 1.61 & 0.45 & $12.90^{* *}$ & 1.47 & 0.45 & $10.54^{* *}$ & 1.51 & 0.43 & $12.33^{* * *}$ \\
\hline Implicit association (IA) & 0.52 & 0.67 & 0.61 & 0.45 & 0.67 & 0.46 & 0.66 & 0.65 & 1.04 \\
\hline Attitude strength (AS) & 0.83 & 0.56 & 2.22 & 0.97 & 0.38 & $6.50^{*}$ & 0.13 & 0.23 & 0.34 \\
\hline Nagelkerkes $R^{2}$ & & & $0.33^{* * *}$ & & & $0.40^{* * *}$ & & & $0.31^{* * *}$ \\
\hline \multicolumn{10}{|l|}{ Step 2} \\
\hline $\mathrm{EA} \times \mathrm{IA}$ & 2.81 & 1.68 & $2.79^{(*)}$ & 1.70 & 1.53 & 1.24 & 2.91 & 1.47 & $3.92^{(*)}$ \\
\hline $\mathrm{EA} \times \mathrm{AS}$ & -1.84 & 1.29 & 2.04 & -0.30 & 0.72 & 0.18 & 0.89 & 0.66 & 1.83 \\
\hline $\mathrm{IA} \times \mathrm{AS}$ & -3.89 & 1.57 & $6.14^{*}$ & -2.17 & 0.99 & $4.77^{*}$ & -1.90 & 0.80 & $5.62^{*}$ \\
\hline Nagelkerkes $R^{2}$ & & & $0.48^{* *}$ & & & $0.49^{*}$ & & & $0.45^{* *}$ \\
\hline \multicolumn{10}{|l|}{ Step 3} \\
\hline $\mathrm{EA} \times \mathrm{IA} \times \mathrm{AS}$ & -1.01 & 0.49 & 0.08 & 2.41 & 2.36 & 3.85 & 0.81 & 2.32 & 0.12 \\
\hline Nagelkerkes $R^{2}$ & & & 0.48 & & & 0.51 & & & 0.45 \\
\hline
\end{tabular}

Note: $N=78 ; B=$ unstandardised Beta coefficient; $S E=$ standard error of $B ;{ }^{(*)} p<0.10,{ }^{*} p<0.05,{ }^{* *} p<0.01,{ }^{* * *} p<0.001$.

three-way interaction term was included but was not a significant predictor $(B=0.45, S E=3.13, p=0.77)$, Nagelkerkes $R^{2}=0.48$ remained. Consequently, the three-way interaction could be eliminated [31]. The two further analyses with the more robust indicators involvement and attitude certainty corroborated the first analysis outcome (see Table 2) - involvement and attitude certainty moderated the relation between implicit association and behaviour, too.

To interpret the interaction between the implicit association and attitude strength in detail, the predicted probabilities of taking a donor card as derived from the logistic model were plotted for a range of the IAT values [31]. As Figure 1 shows, for participants who had not reflected about signing a card (low attitude strength), the likelihood of taking a donor card increased with an increasing positive implicit association; 34\% variance in the behavioural likelihood was explained. Conversely, for participants who had already thought about signing a donor card (high strength group), the link between behavioural likelihood and implicit associations was weaker $\left(R^{2}\right.$ $=0.11$ ), as expected. The relation was slightly negative. The simple slopes analyses for involvement and attitude certainty showed the same directions.

In sum, the results show that when both attitude measures are entered simultaneously as predictors, only the explicit attitude measure predicts significantly whether someone takes an organ donor card or not. More importantly, the data provide evidence for the moderating role of attitude strength. Implicit associations were observed more effective predictor of taking a donor card in case of low attitude strength.

\section{Discussion}

\subsection{Implicit Associations and Attitude Strength}

The observed results confirmed the proposed moderating impact of attitude strength on the relation between implicit associations and organ donation behaviour. When considered simultaneously with an explicit attitude measure, the implicit measure had no significant impact on behaviour - the explicit remained the only significant predictor. However, congruent with expectation, across three attitude strength indicators consistently the strength and the implicit measures interacted: When the attitude strength was weak, increasing positive implicit associations were related to an increased probability of taking a donor card. 

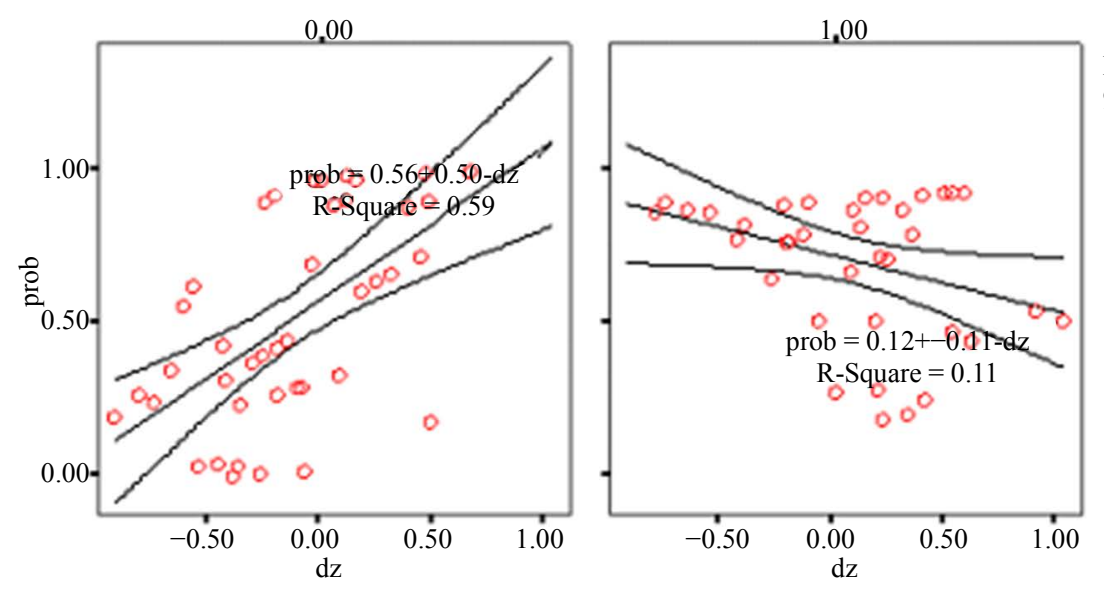

Linear Regression with

95.00\% Mean Prediction Interval

Figure 1. Simple slopes for the interaction between implicit associations and strength indicator "cognitive elaboration" on probability of taking an organ donor card.

Deliberate behaviour requires reliable knowledge and evaluations to come up with a behavioural decision, e.g. [19]. In the case of insufficient prior evaluations, further information is likely to be needed. Therefore, it seems highly possible that impulsive reactions were used as affective information to confirm one's reflective associations [27]. When the attitude strength was indicated as strong, implicit associations barely influenced the deliberate behaviour, and the reflective system seemed to dominate card taking. This dominance can be explained by the assumption that strong attitudes are based on elaboration, which leads to more consistent and accessible schema [22] [32]. Additionally, when the impulsive and reflective system activates conflicting schemata, the reflective system more likely controls the behaviour [24]. The slightly negative link between the implicit association and donation behaviour in the case of high attitude strength might underline the dominance of the reflective system. It seems possible that in the high strength group, negative impulsive reactions were even overcompensated. However, this interpretation is speculative and needs further investigation.

\subsection{Interplay between Explicit and Implicit Attitude Measures}

In line with the results obtained by Perugini [14], an interaction —-though marginally significant—between implicit and explicit attitude measures was observed. The interactive pattern suggests that the prediction of taking an organ donor card or not is more effective when implicit and explicit attitude measures are in the same direction. Although this interaction showed only a trend towards statistical significance, it appeared independently of attitude strength. The implicit association's direct impact on card taking behaviour was far from significant ( $p=$ 0.76). Accordingly, the present data provide little evidence for an additive model. Still, this missing additive pattern should be interpreted with caution, since implicit and explicit attitude measures can be dissociated for different reasons, e.g. [16] [32]. The same is true for the correlation between the implicit and explicit attitude measures. In this respect, the measures' correlation might have been stronger if the measured constructs would be connected closer. More specifically, in our IAT we combined organ donation with anxiety and calmness items, which is slightly different than a global positive or negative evaluation used in the explicit attitude measure.

\subsection{Positive IAT Effect}

Contrary to expectation, we found a positive-although small—overall IAT effect. Since we counterbalanced the IAT block order, at least two other explanations than presentation order seem possible. First, our IAT-donation could be contaminated by extra-personal associations [33]. If so, the present IAT may reflect knowledge of common attitudes towards organ donation but fail to detect person's idiosyncratic attitudes, cf. [34]. Second, the chosen non-donation category might not represent a real contrast category. Furthermore, while the donation category was coherent, the non-donation was not. However, other studies have successfully used non-coherent categories, e.g. [8]. More importantly, to prevent a figure-ground asymmetry [35] when constructing the IATdonation categories we controlled for the included words' valences and familiarity. Thus, it seems unlikely that 
the observed positive IAT effect was merely due to the fact that the alternative category was not a single coherent category.

\subsection{Limitations and Conclusions}

Some limitations of this contribution should be acknowledged. First, it would be desirable to validate our findings experimentally, e.g. by varying deliberate behaviour conditions. A second shortcoming is the behaviour measure. Taking a donor card, admittedly, does not necessarily indicate signing it. Indeed, to control actual signing behaviours will have been a stronger behaviour measure. Still, anonymously taking an offered organ donor card is a potentially important step that suggests some movement in the direction of becoming an organ donor. Third, to validate the moderating impact of attitude strength on the relationship between implicit attitudes and deliberate behaviours, tests should be performed in domains other than organ donation.

Despite these limitations, the present results suggest that dissociations between implicit attitude measures and deliberate behaviours can be due to attitude strength. While impulsive reactions seem to be used as affective information to form a decision when nonexistent or weak summary evaluations exist, reflective outputs prevail in the case of strong attitudes. However, the present results mirror the predictive power of explicit attitude measures as well.

Our study examined implicit associations in a domain not previously examined—organ donation behaviour. More importantly, the present contribution offers a new explanation as to why implicit associations sometimes do and sometimes do not predict more deliberate behaviours. Additionally, the results offer practical recommendations that communication strategies designed to foster attitude strength can help to overcome implicit associations' impact on the organ donation decision.

\section{References}

[1] Moloney, G. and Walker, I. (2002) Talking about Transplants: Social Representations and the Dialectical, Dilemmatic Nature of Organ Donation and Transplantation. British Journal of Social Psychology, 41, 299-320. http://dx.doi.org/10.1348/014466602760060264

[2] Van den Berg, H., Manstead, A.S.R., van der Pligt, J. and Wigboldus, D.H.J. (2005) The Role of Affect in Attitudes toward Organ Donation and Donor-Relevant Decisions. Psychology \& Health, 20, 789-802. http://dx.doi.org/10.1080/14768320500161786

[3] Greenwald, A.G., Banaji, M.R., Rudman, L.A., Farnham, S.D., Nosek, B.A. and Mellott, D.S. (2002) A Unified Theory of Implicit Attitudes, Stereotypes, Self-Esteem, and Self-Concept. Psychological Review, 102, 4-27. http://dx.doi.org/10.1037/0033-295X.102.1.4

[4] Greenberg, J., Solomon, S. and Pyszczynski, T. (1997) Terror Management Theory of Self-Esteem and Social Behaviour: Empirical Assessments and Conceptual Refinements. In: Zanna, M.P., Ed., Advances in Experimental Social Psychology, Vol. 29, Academic Press, New York, 61-139.

[5] Greenwald, A.G., McGhee, D.E. and Schwartz, J.L.K. (1998) Measuring Individual Differences in Implicit Cognition: The Implicit Association Test. Journal of Personality and Social Psychology, 74, 1464-1480. http://dx.doi.org/10.1037/0022-3514.74.6.1464

[6] Greenwald, A.G. and Nosek, B.A. (2001) Health of the Implicit Association Test at Age 3. Zeitschrift für Experimentelle Psychologie, 48, 85-93. http://dx.doi.org/10.1026//0949-3946.48.2.85

[7] Nosek, B.A., Greenwald, A.G. and Banaji, M.R. (2007) The Implicit Association Test at Age 7: A Methodological and Conceptual Review. In: Bargh, J.A., Ed., Automatic Processes in Social Thinking and Behaviour, Psychology Press, New York, 265-292.

[8] Marsh, K.L., Johnson, B.T. and Scott-Sheldon, L.A.J. (2001) Heart versus Reason in Condom Use: Implicit versus Explicit Attitudinal Predictors of Sexual Behaviour. Zeitschrift für Experimentelle Psychologie, 48, 161-175. http://dx.doi.org/10.1026//0949-3946.48.2.161

[9] Schnabel, K., Banse, R. and Asendorpf, J. (2006) Assessment of Implicit Personality Self-Concept Using the Implicit Association Test (IAT): Concurrent Assessment of Anxiousness and Angriness. British Journal of Social Psychology, 45, 373-396. http://dx.doi.org/10.1348/014466605X49159

[10] Greenwald, A.G., Poehlman, T.A., Uhlmann, E. and Banaji, M.R. (2009) Understanding and Using the Implicit Association Test: III. Meta-Analysis of Predictive Validity. Journal of Personality and Social Psychology, 97, 17-41. http://dx.doi.org/10.1037/a0015575

[11] Dovidio, J.F., Kawakami, K. and Gaertner, S.L. (2002) Implicit and Explicit Prejudice and Interracial Interaction. 
Journal of Personality and Social Psychology, 82, 62-68. http://dx.doi.org/10.1037/0022-3514.82.1.62

[12] Friese, M., Bluemke, M. and Wänke, M. (2007) Predicting Voting Behaviour with Implicit Attitude Measures. The 2002 German Parliamentary Election. Experimental Psychology, 54, 247-255. http://dx.doi.org/10.1027/1618-3169.54.4.247

[13] Karpinski, A. and Hilton, J.L. (2001) Attitudes and the Implicit Association Test. Journal of Personality and Social Psychology, 81, 774-778. http://dx.doi.org/10.1037/0022-3514.81.5.774

[14] Perugini, M. (2005) Predictive Models of Implicit and Explicit Attitudes. British Journal of Social Psychology, 44, 2945. http://dx.doi.org/10.1348/014466604X23491

[15] Perugini, M. and Prestwich, A. (2007) The Gatekeeper: Individual Differences Are Key in the Chain from Perception to Behaviour. European Journal of Personality, 21, 303-317. http://dx.doi.org/10.1002/per.633

[16] Hofmann, W., Gschwendner, T., Nosek, B.A. and Schmitt, M. (2005) What Moderates Implicit—Explicit Con- sistency? European Review of Social Psychology, 16, 335-390. http://dx.doi.org/10.1080/10463280500443228

[17] Krosnick, J.A. and Petty, R.E. (1995) Attitude Strength: Antecedents and Consequences. Lawrence Erlbaum, Mahwah.

[18] Bassili, J.N. (2008) Attitude Strength. In: Crano, W.D. and Prislin, R., Eds., Attitudes and Attitude Change, Psychology Press, New York, 237-234.

[19] Visser, P.S., Krosnick, J.A. and Simmons, P.J. (2003) Distinguishing the Cognitive and Behavioural Consequences of Attitude Importance and Certainty: A New Approach to Testing the Common-Factor Hypothesis. Journal of Experimental Social Psychology, 39, 118-141. http://dx.doi.org/10.1016/S0022-1031(02)00522-X

[20] Conner, M., Perugini, M., O’Gorman, Ayres, K. and Prestwich, A. (2007) Relations between Implicit and Explicit Measures of Attitudes and Measures of Behavior: Evidence of Moderation by Individual Difference Variables. Personality and Social Psychology Bulletin, 33, 1727-1740. http://dx.doi.org/10.1177/0146167207309194

[21] Nosek, B.A. (2005) Moderators of the Relationship between Implicit and Explicit Evaluation. Journal of Experimental Psychology: General, 134, 565-584. http://dx.doi.org/10.1037/0096-3445.134.4.565

[22] Fazio, R.H. (1995) Attitudes as Object-Evaluation Associations: Determinants, Consequences, and Correlates of Attitude Accessibility. In: Petty, R.E. and Krosnick, J.A., Eds., Attitude Strength: Antecedents and Consequences, Lawrence Erlbaum, Mahwah, 247-283.

[23] Greenwald, A.G. and Banaji, M.R. (1995) Implicit Social Cognition: Attitudes, Self-Esteem, and Stereotypes. Psychological Review, 102, 4-27. http://dx.doi.org/10.1037/0033-295X.102.1.4

[24] Strack, F. and Deutsch, R. (2005) Reflective and Impulsive Determinants of Social Behaviour. Personality and Social Psychology Review, 8, 220-247. http://dx.doi.org/10.1207/s15327957pspr0803_1

[25] Petty, R.E., Haugtvedt, C.P. and Smith, S.M. (1995) Elaboration as a Determinant of Attitude Strength: Creating Attitudes That Are Persistent, Resistant, and Predictive of Behaviour. In: Petty, R.E. and Krosnick, J.A., Eds., Attitude Strength: Antecedents and Consequences, Lawrence Erlbaum, Mahwah, 93-130.

[26] Rudman, L.A. (2004) Sources of Implicit Attitudes. Current Directions in Psychological Science, 13, 79-82. http://dx.doi.org/10.1111/j.0963-7214.2004.00279.x

[27] Clore, G.L., Gasper, K. and Garwin, E. (2001) Affect as Information. In: Forgas, J.P., Ed., Handbook of Affect and Social Cognition, Lawrence Erlbaum, Mahwah, 121-144.

[28] Egloff, B., Schwerdtfeger, A. and Schmuckle, S.C. (2005) Temporal Stability of the Implicit Association Test-Anxiety. Journal of Personality Assessment, 84, 82-88. http://dx.doi.org/10.1207/s15327752jpa8401_14

[29] Greenwald, A.G., Nosek, B.A. and Banaji, M.R. (2003) Understanding and Using the Implicit Association Test: I. An Improved Scoring Algorithm. Journal of Personality and Social Psychology, 85, 197-216. http://dx.doi.org/10.1037/0022-3514.85.2.197

[30] Aiken, L.S. and West, S.G. (1991) Multiple Regression: Testing and Interpreting Interactions. Sage, Newbury Park.

[31] Jaccard, J. (2004) Interaction Effects in Logistic Regression. Sage, Thousand Oaks.

[32] Petty, R.E. and Cacioppo, J.T. (1986) The Elaboration Likelihood Model of Persuasion. In: Berkowitz, L., Ed., Advances in Experimental Social Psychology, Vol. 19, Academic Press, New York, 123-205.

[33] Olson, M.A. and Fazio, R.H. (2004) Reducing the Influence of Extrapersonal Associations on the Implicit Association Test: Personalizing the IAT. Journal of Personality and Social Psychology, 86, 653-667. http://dx.doi.org/10.1037/0022-3514.86.5.653

[34] Fiedler, K., Messner, C. and Bluemke, M. (2006) Unresolved Problems with the "I", the "A" and the "T": A Logical and Psychometric Critique of the Implicit Association Test (IAT). European Review of Social Psychology, 17, 74-147. http://dx.doi.org/10.1080/10463280600681248

[35] Rothermund, K. and Wentura, D. (2001) Figure-Ground Asymmetries in the Implicit Association Test (IAT). Zeitschrift für Experimentelle Psychologie, 48, 94-106. http://dx.doi.org/10.1026//0949-3946.48.2.94 
Scientific Research Publishing (SCIRP) is one of the largest Open Access journal publishers. It is currently publishing more than 200 open access, online, peer-reviewed journals covering a wide range of academic disciplines. SCIRP serves the worldwide academic communities and contributes to the progress and application of science with its publication.

Other selected journals from SCIRP are listed as below. Submit your manuscript to us via either submit@scirp.org or Online Submission Portal.
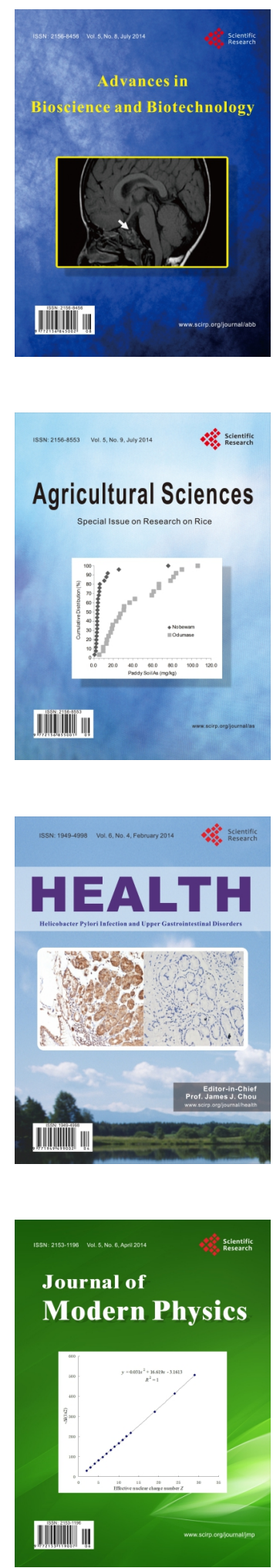
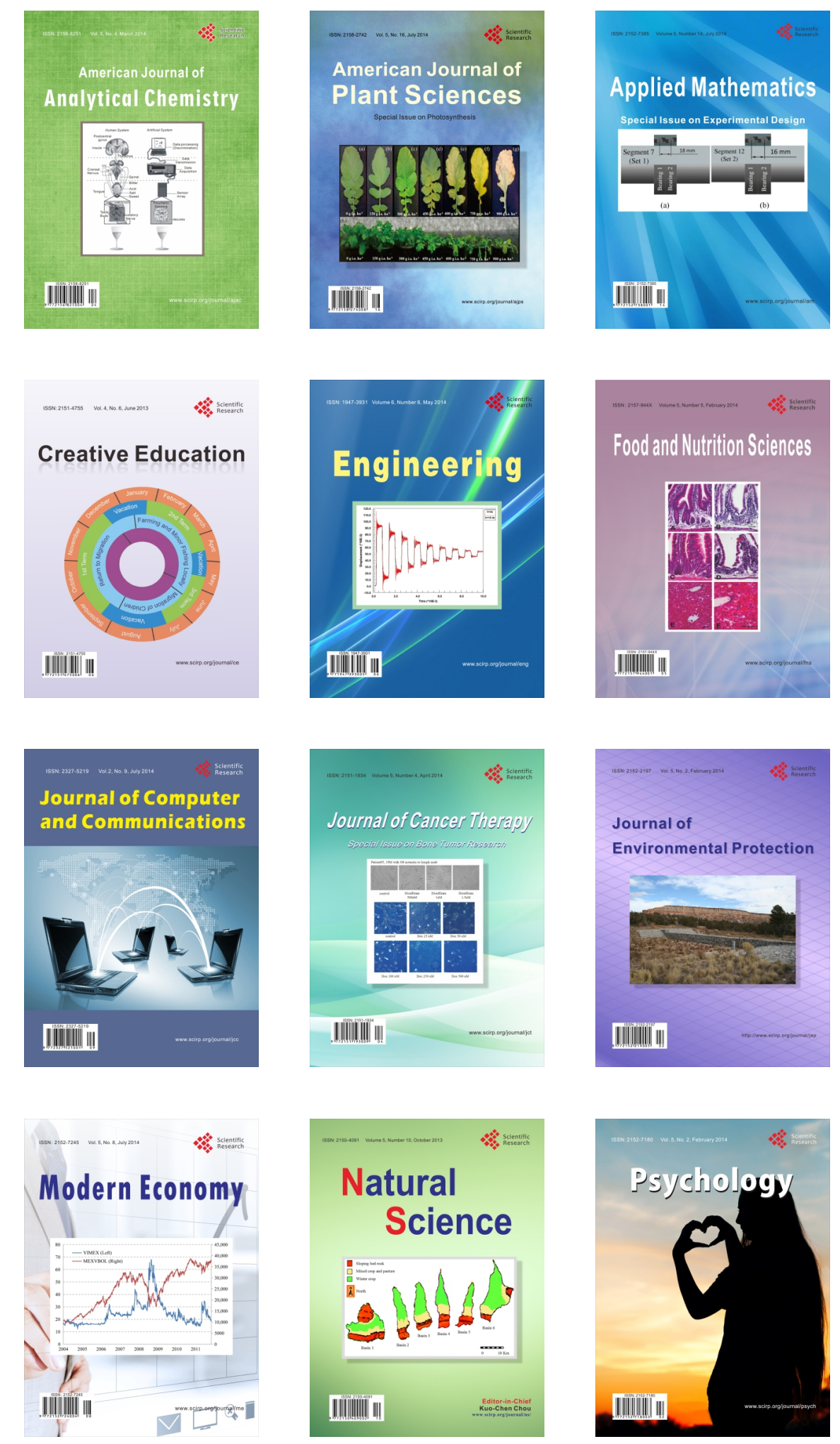